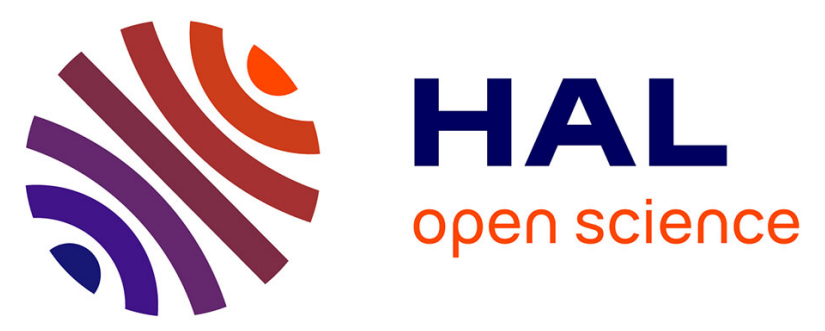

\title{
Hybridizations between formae speciales of Venturia inaequalis pave the way for a new biocontrol strategy to manage fungal plant pathogens
}

Valérie Caffier, Jason Shiller, Marie-Noëlle Bellanger, Jerome Collemare, Pascale Expert, Pierre P. Gladieux, Claire Pascouau, Mélanie Sannier, Bruno Le Cam

\section{To cite this version:}

Valérie Caffier, Jason Shiller, Marie-Noëlle Bellanger, Jerome Collemare, Pascale Expert, et al.. Hybridizations between formae speciales of Venturia inaequalis pave the way for a new biocontrol strategy to manage fungal plant pathogens. Phytopathology, 2022, 112 (7), pp.1401-1405. 10.1094/phyto-0521-0222-sc . hal-03560861

\section{HAL Id: hal-03560861 https://hal.inrae.fr/hal-03560861}

Submitted on 7 Feb 2022

HAL is a multi-disciplinary open access archive for the deposit and dissemination of scientific research documents, whether they are published or not. The documents may come from teaching and research institutions in France or abroad, or from public or private research centers.
L'archive ouverte pluridisciplinaire HAL, est destinée au dépôt et à la diffusion de documents scientifiques de niveau recherche, publiés ou non, émanant des établissements d'enseignement et de recherche français ou étrangers, des laboratoires publics ou privés.

$$
\text { Copyright }
$$


1 Hybridizations between formae speciales of Venturia inaequalis pave the way for a new

2 biocontrol strategy to manage fungal plant pathogens

3

4 Valérie Caffier ${ }^{1+*}$, Jason Shiller ${ }^{1+}$, Marie-Noëlle Bellanger ${ }^{1}$, Jérôme Collemare ${ }^{2}$, Pascale

5 Expert $^{1}$, Pierre Gladieux ${ }^{3}$, Claire Pascouau ${ }^{1}$, Mélanie Sannier ${ }^{1}$, Bruno Le Cam ${ }^{1}$

6

$7 \quad{ }^{1}$ Univ Angers, INRAE, Institut Agro, IRHS, SFR QUASAV, 49000 Angers, France

$8 \quad{ }^{2}$ Westerdijk Fungal Biodiversity Institute, Uppsalalaan 8, 3584 CT Utrecht, Netherlands

$9 \quad{ }^{3} \mathrm{PHIM}$ Plant Health Institute, Univ Montpellier, INRAE, CIRAD, Institut Agro, IRD, Montpellier,

10 France

$11{ }^{*}$ Corresponding author: V. Caffier; E.mail: valerie.caffier@inrae.fr 


\section{Abstract}

Hybridization and adaptation to new hosts are important mechanisms of fungal disease emergence. Evaluating the risk of emergence of hybrids with enhanced virulence is then key to develop sustainable crop disease management. We evaluated this risk in Venturia inaequalis, the fungus responsible for the common and serious scab disease on Rosaceae hosts, including apple, pyracantha and loquat. Field isolates from these three hosts and progenies obtained from five crosses between formae speciales isolates collected from pyracantha (f.sp. pyracantha) and apple (f.sp. pomi) were tested for their pathogenicity on the three hosts. We confirmed a strict host specificity between isolates from apple and pyracantha, and showed that most isolates were able to cause disease on loquat. None of the 251 progeny obtained from five crosses between $V$. inaequalis f.sp. pyracantha and $V$. inaequalis f. sp. pomi could infect apple. If confirmed on more crosses, the inability of the hybrids to infect apple could lead to a novel biocontrol strategy based on a sexual hijacking of $V$. inaequalis f.sp. pomi by a massive introduction of $V$. inaequalis $f . s p$. pyracantha in apple orchards. This strategy, analogous to the sterile insect approach, could lead to the collapse of the population size of $V$. inaequalis and dramatically reduce the use of chemicals in orchards.

Keywords : Host specificity, Biological control, Crossing experiments, Scab, Apple, Firethorn, Eriobotrya, Sexual hijacking

Plant-pathogenic fungi show variation in the width of their host range, from generalist pathogens that cause disease on multiple host species to specialized pathogens that infect a single host species. Fungal species strictly specialized to different hosts are referred to as formae speciales. Reproductive barriers between lineages - including formae speciales - 
specialized to different hosts may be incomplete, which may lead to hybridization (Le Gac and Giraud 2008; Depotter et al. 2016). If hybrids are less fit than their parents on the same host, they should ultimately disappear, but still may act as a "genetic bridge" allowing transfer of pathogenicity traits from one species to another by backcrossing (Brasier 2001; Feurtey and Stukenbrock 2018; Stukenbrock et al. 2012). Hybridization can also result in extreme phenotypes, a phenomenon referred to as transgressive segregation (Rieseberg et al. 1999). Hybrid individuals can display increased virulence, as observed for hybrids between anther smut pathogens Microbotryum lychnidis-dioicae and M. silenes-dioicae (Gibson et al. 2014), or display an expanded or new host range such as in the triticale pathogen Blumeria graminis f.sp. triticale that was formed by hybridization between the wheat and rye pathogens $B$. graminis f.sp. tritici and B. graminis f.sp. secalis (Menardo et al. 2016). As hybridization of different formae speciales can be a driving force in the emergence of new diseases with expanded host ranges we investigated the potential for this phenomenon to occur in the fungal pathogen Venturia inaequalis.

$V$. inaequalis is responsible for scab disease on apple (Malus $\mathrm{x}$ domestica), the most cultivated fruit tree in temperate areas worldwide. Apple scab reduces both the quality and quantity of fruit. The control of the disease is mainly based on the use of fungicides. For a sustainable and risk-free environmental control of apple scab, there is a need to develop the use of apple resistant cultivars together with sanitation (Didelot et al. 2016), and to develop new control methods, especially for biological control which lacks efficiency in orchards (Carisse and Rolland 2004; Kohl et al. 2015). V. inaequalis also causes scab disease on other Rosaceae hosts, including pyracantha and loquat (Jones and Aldwinckle 1991; Sivanesan 1977). Loquat (Eriobotrya japonica Lindl.) is grown for fruit production in regions with subtropical climate, while pyracantha (Pyracantha spp) is grown as an ornamental plant sometimes planted in 
hedges in an area extending from Southwest Europe to Southeast Asia. A strict host specificity has been observed for isolates of $V$. inaequalis from pyracantha, which are able to cause disease on pyracantha but not on apple (i.e. V. inaequalis f.sp. pyracantha), and isolates from apple, which are able to cause disease on apple but not on pyracantha (i.e. V. inaequalis f.sp. pomi) (Le Cam et al. 2002). It was suggested that these two formae speciales are in "a process of isolation due to host specialization" (Le Cam et al. 2002). The status of isolates from loquat is less clear. Raabe and Gardner (1972) considered isolates from pyracantha and from loquat as belonging to the same forma specialis because they were able to infect both pyracantha and loquat. Sanchez-Torres et al. (2009) showed that four isolates of $V$. inaequalis sampled on apple were not able to cause disease on loquat. Gladieux et al. (2010) used six nuclear loci to show that $V$. inaequalis populations from loquat and those from pyracantha have more recently diverged than $V$. inaequalis populations from apple and those from pyracantha. Recently, using whole genome sequencing data, Le Cam et al. (2019) confirmed that populations of $V$. inaequalis isolated from apple, pyracantha and loquat represent distinct genetic lineages.

The aim of this study was to investigate the host specificity of $V$. inaequalis isolates from apple, pyracantha and loquat, and to test the hypothesis that crosses between $V$. inaequalis formae speciales represent a disease emergence risk by generating hybrids pathogenic on both hosts, or potentially with higher virulence on existing hosts.

A strict host specificity was observed on apple and pyracantha, while most $V$. inaequalis isolates were able to cause disease on loquat.

Thirty-two monoconidial isolates were recovered from scabbed leaves of apple (11 isolates, named Pomi), pyracantha (11 isolates, named Pyr) and loquat (10 isolates, named Loq), 
sampled from different locations in nine, seven and seven different countries, respectively (Table S1). These isolates were checked as being non-clonal using eight Simple Sequence Repeat markers (SSRs) developed on V. inaequalis (Table S2; Guérin et al. 2004; Guérin et al. 2007; Tenzer et al. 1999). These isolates were inoculated individually on two apple cultivars (Gala and Top Red), four pyracantha cultivars (Kasan, Orange Charmer, Red Column and Soleil d'or), and two loquat cultivars (Peluche and Alfonso). These cultivars were selected for their susceptibility to scab (Bertrand et al. 1992; Bus et al. 2011; Sanchez-Torres et al. 2009). Plants were grown in a glasshouse in a scab-free environment, and transferred into a growth chamber for the tests of pathogenicity. Actively growing plants with expanding leaves which are highly susceptible to $V$. inaequalis were used in six different experiments, because all isolates could not be inoculated simultaneously across all hosts in the growth chamber. In order to avoid cross-contamination during inoculation, plants were placed in polycarbonate compartments and each compartment was inoculated with a single isolate. Each experiment included isolates of each origin and at least one cultivar of each host, except experiment 1 where no pyracantha was present and experiment 6 where no loquat was present. Each isolate was grown on a cellophane sheet placed on malt-agar medium at $17^{\circ} \mathrm{C}$ to obtain spores (Caffier et al. 2014). Spores were suspended in water by shaking the cellophane sheet. After filtration through medical gauze, the spore suspension was adjusted to a final concentration of $2.5 \times 10^{5}$ spores $\mathrm{ml}^{-1}$ and was inoculated using a manual sprayer on three plants of each cultivar. After inoculation, plants were kept in darkness under a plastic sheet to maintain leaf wetness. Climatic conditions in the growth chamber were set to $95 \%$ of relative humidity at $17^{\circ} \mathrm{C}$ for 48 hours. Afterwards, the plastic sheet was removed and the relative humidity was reduced to $80 \%$ at day and $90 \%$ at night, with 12 hours of light per day. In order to evaluate 
the ability of each isolate to cause disease, the presence/absence of scab symptoms on each plant was scored at 14, 21 and 28 days post inoculation.

Not all Pomi and Pyr isolates caused symptoms on their respective hosts, while all Loq isolates could infect both loquat cultivars (Figure 1). This result suggests the existence of resistance genes in the apple cultivar Top Red and in all four pyracantha cultivars. No Pyr isolate was able to cause disease on the apple cultivars, and no Pomi isolate was able to cause disease on any of the four pyracantha cultivars (Figure 1), which agrees with previous results and confirms the status of formae speciales $V$. inaequalis f.sp. pomi and $V$. inaequalis f.sp. pyracantha (Le Cam et al. 2002). All Pyr isolates were able to cause disease on loquat, which agrees with data from Raabe and Gardner (1972). However, the reciprocal was not true, as only one of the 10 Loq isolates was able to cause disease on pyracantha. Nine out of 11 Pomi isolates were able to cause disease on the loquat cultivars Peluche and/or Alfonso. No Loq isolate was pathogenic on apple except isolate 2305 that was previously described as resulting from a one-off shift from apple to loquat, on the basis of its polymorphism at six nuclear loci (Gladieux et al. 2010). To further investigate the pathogenicity of isolates on loquat and compare their aggressiveness in relation to their host of origin, five isolates from each host were inoculated on both loquat cultivars (three plants per cultivar) in the same experiment. Loquat plants were randomized within three blocks to have in each block one plant replicate for each isolate and each cultivar. We performed a quantitative scoring through visual evaluation of the percentage scabbed leaf area 21 days post inoculation, from no disease to $100 \%$ leaf area scabbed. The effect of the host of origin on the percentage scabbed leaf area was tested in $R$ 4.0.3 ( $R$ Core Team 2020) using a linear mixed effect model with the LMER package (Kuznetsova et al. 2017). The 'isolate' factor was treated as a random factor nested within the 'host of origin' factor. The data were Log transformed prior to statistical analysis. This 
experiment showed that the Pomi isolates were significantly less aggressive on the loquat cultivars Peluche and Alfonso than the Pyr and Loq isolates (Figure 2). There was no significant difference in aggressiveness on loquat between Pyr and Loq isolates. This result agrees with the scenario proposed by Gladieux et al. (2010), where populations from loquat and pyracantha have diverged more recently than populations from apple and pyracantha.

Most progenies from a cross between f.sp. pomi and f.sp. pyracantha can infect pyracantha,

but none can infect apple.

As $V$. inaequalis f.sp. pyracantha and $V$. inaequalis f.sp. pomi isolates can be crossed in vitro (Le Cam et al. 2002), we tested the hypothesis that hybrids may have increased virulence on one of the hosts (apple or pyracantha) or that they may have an extended host range (able to cause disease on both apple and pyracantha).

We performed five different crosses, three crosses between one Pyr isolate $(1669,1381$ and 1383) and one Pomi isolate (EU-B04 and 2556) and two crosses between one Pyr isolate (1387 and 2299) and a mixture of five Pomi isolates $(104+2416+2429+2444+2557$, Table S1, Table 1), on sterile foliar disks of apple cultivar Gala, as described in Le Cam et al. (2002). The use of a mixture of isolates enabled us to diversify the origin of the Pomi parent. Mature pseudothecia were recovered from the leaf disks and crushed individually to obtain a suspension of ascospores that was spread on malt (10g per liter) agar. After 24 to 48 hours of incubation at $17^{\circ} \mathrm{C}$, germinated ascospores were picked up individually with a needle under a stereomicroscope and transferred to new medium. To ensure the hybrid status of each progeny, we performed a multilocus genotyping using eight SSRs (Table S2; Guérin et al. 2004; 
one progeny, checked as being hybrids by SSRs, and the parental isolates were grown on cellophane sheets.

Spore suspensions from 37 progeny of the cross between 1669 and EU-B04 isolates and from both parents were adjusted to a final concentration of $2.5 \times 10^{5}$ spores $\mathrm{ml}^{-1}$ and inoculated in a single experiment on three plants of pyracantha cultivar Kasan as described above. Pyracantha plants were randomized within three blocks to have in each block one host replicate for each isolate. At 15, 20, 23 and 27 days post inoculation, disease severity was measured visually as the percentage of sporulating leaf area on the most scabbed leaf on each plant. These 37 progeny produced a large range of disease levels on the pyracantha cultivar Kasan (Figure 3). No progeny was more aggressive than the Pyr parent 1669 . Only one progeny isolate was unable to cause disease on Kasan, similarly to the parental Pomi isolate. All other progenies gave a disease level that was intermediate between the parental Pomi isolate EUB04 (0\% leaf area scabbed) and the parental Pyr isolate 1669 (90\% leaf area scabbed), suggesting a complex genetic determinism for pathogenicity on this host. This result differed from previous studies in other pathosystems, for which a few genes explained host specificity. For example, two to four genes may be responsible for the pathogenicity of the two sibling species Ceratocystis manginecan and Ceratocystis fimbriata on Acacia mangum and Ipomoea batatas (Fourie et al. 2018; Fourie et al. 2019). Similarly, one to two genes have been shown to be responsible for host specificity of Magnaporthe oryzae on foxtail millet in a cross between an isolate pathogenic on wheat and an isolate pathogenic on foxtail millet (Murakami et al. 2003), and three genes have been shown to be responsible for host specificity of $M$. oryzae on wheat in a cross between an isolate pathogenic on rice and an isolate pathogenic on wheat (Tosa et al. 2006). The loss of a single locus, AVR-Co39, was involved in the host shift of M. oryzae from Setaria millet to rice (Couch et al. 2005). In the same way a single gene was 
shown to be involved in the host specificity of Blumeria graminis f.sp. secalis on wheat (Tosa 1994).

The 251 progeny obtained from the five different crosses were inoculated on apple, either four seedlings obtained from seeds collected from the apple cultivar Gala or six apple plants grafted on the rootstock MM106 (three Gala and three Golden Delicious) at a concentration of 2 to $4 \times 10^{5}$ spores $\mathrm{ml}^{-1}$. The viability of each inoculum was checked by counting germinated and non-germinated spores over a total of 100 spores for each isolate 24 hours after the deposition of the suspension on malt agar incubated in darkness at $17^{\circ} \mathrm{C}$. Only progeny with a concentration higher than $8 \times 10^{4}$ viable spores $\mathrm{ml}^{-1}$ were kept for analysis. Nine experiments were needed to test all progeny. In each experiment, two parental isolates (a Pomi isolate and a Pyr isolate) were used as control to check that the conditions were suitable for scab infection. None of the 251 progeny were pathogenic on apple, i.e. all progeny behaved as the Pyr parental isolates 1669, 1381, 1383, 1387 and 2299 on apple, whereas the Pomi isolate used as a control gave at least $45 \%$ and $80 \%$ leaf area scabbed (mean of the most infected leaf of three plants for each cultivar), on Gala and Golden Delicious plants, respectively. This result is consistent with the study of Tosa et al. (2006) on M. oryzae, which showed that none of the 94 progeny obtained from a cross between an isolate pathogenic on rice and an isolate pathogenic on wheat was virulent on rice. Comparative genomic analysis of these progeny and parental isolates are needed to understand pathogenicity mechanisms and to identify putative genes involved in specificity of $V$. inaequalis on apple and pyracantha.

Towards a new strategy of biocontrol against apple scab.

While hybridization between divergent populations or phytopathogenic species is often 
enhance its virulence, we showed that hybridization between formae speciales of $V$. inaequalis can be detrimental to fungal pathogens. If confirmed on more crosses, our finding that hybrids are non-pathogenic on apple paves the way for a new biocontrol method to collapse pathogen population size in apple orchards. Indeed, we propose to exploit this finding for biological control based on a sexual hijacking strategy, similar to the sterile insect technique proposed by Vanderplank (1944) to control the tsetse fly, which is largely developed now on many insect species (Klassen and Curtis 2005).

As sexual reproduction is the main way for $V$. inaequalis f.sp. pomi to survive in winter in temperate areas and as heterothallic mating is induced on dead leaves after leaf fall (MacHardy 1996), a massive introduction in autumn of Pyr isolates representing the two mating types by spraying of spores on the senescent leaves before or just after leaf fall should lead to the production of hybrid ascospores unable to cause disease on apple in spring. This strategy is expected to be efficient to reduce primary inoculum throughout most regions of apple production, except maybe in regions with mild winter where $V$. inaequalis can survive as asexual spores within buds (Holb et al. 2005; Passey et al. 2017). To maximize impact on apple scab, this strategy may be associated with other methods, like sanitary measures and use of resistant cultivars (Didelot et al. 2016).

Because the proposed biocontrol strategy is based on an organism which is widely distributed, that has not undergone genetic modification, and whose effect is highly specific, we do not expect any toxicity to humans or the environment, with the possible exception of pyracantha shrubs located in the immediate vicinity of orchards. The efficiency of this sexual hijacking strategy remains to be evaluated experimentally in orchards, and so does the risk of emergence of hybrids pathogenic on apple trees or other cultivated Rosaceae hosts. Since this 
226 strategy could be implemented with other fungi having formae speciales and a sexual stage,

227 our work opens a new area of research in the biocontrol of plant pathogenic fungi. 
Page 12 of 17

\section{Patent for this novel strategy of biocontrol}

Patent application PCT/FR2020/052580 « Méthode de bio-contrôle pour lutter contre la propagation des champignons et oomycètes phytopathogènes ", jointly filed on $21 / 12 / 2020$ by INRAE, Université d'Angers, Institut National Supérieur des Sciences Agronomiques, Agroalimentaires, Horticoles et Paysage.

\section{Acknowledgments}

We thank the staff of the PHENOTIC core facility in Angers (https://doi.org/10.15454/U2BWFJ) who ensured the production of the plants and maintenance of plant-growth facilities that allowed us to do this work, and the students C. Granon, S. Alexandre and S. Le Grand who contributed to the multiplication of progeny and the tests of pathogenicity. We also thank Cécilia Multeau and Pascale Barbier for their advice in the development and management of this novel biocontrol project.

\section{Funding}

This work was supported by the Emerfundis-ANR project (grant number 07-BDIV-003), the RFI Végétal project FUNADAPT and by two projects funded by INRAE (Division "Plant Health and Environment" and Direction for Partnership, Transfer and Innovation)." 


\section{References}

Bertrand, H., Cadic, A., and Belin, J. 1992. Pyracantha: origine, description et clé de détermination des principaux taxons. SEDA/PHM-Revue Horticole, Paris, France.

Brasier, C. M. 2001. Rapid evolution of introduced plant pathogens via interspecific hybridization. Bioscience 51:123-133.

Bus, V. G. M., Rikkerink, E. H. A., Caffier, V., Durel, C. E., and Plummer, K. M. 2011. Revision of the nomenclature of the differential host-pathogen interactions of Venturia inaequalis and Malus. Annu. Rev. Phytopathol. 49:391-413.

Caffier, V., Lasserre-Zuber, P., Giraud, M., Lascostes, M., Stievenard, R., Lemarquand, A., van de Weg, E., Expert, P., Denancé, C., Didelot, F., Le Cam, B., and Durel, C. 2014. Erosion of quantitative host resistance in the apple - Venturia inaequalis pathosystem. Infect. Genet. Evol. 27:481-489.

Carisse, O., and Rolland, D. 2004. Effect of timing of application of the biological control agent Microsphaeropsis ochracea on the production and ejection pattern of ascospores by Venturia inaequalis. Phytopathology 94:1305-1314.

Couch, B. C., Fudal, I., Lebrun, M. H., Tharreau, D., Valent, B., van Kim, P., Notteghem, J. L., and Kohn, L. M. 2005. Origins of host-specific populations of the blast pathogen Magnaporthe oryzae in crop domestication with subsequent expansion of pandemic clones on rice and weeds of rice. Genetics 170:613-630.

Depotter, J. R. L., Seidl, M. F., Wood, T. A., and Thomma, B. 2016. Interspecific hybridization impacts host range and pathogenicity of filamentous microbes. Curr. Opin. Microbiol. 32:7-13.

Didelot, F., Caffier, V., Orain, G., Lemarquand, A., and Parisi, L. 2016. Sustainable management of scab control through the integration of apple resistant cultivars in a low-fungicide input system. Agric. Ecosyst. Environ. 217:41-48.

Feurtey, A., and Stukenbrock, E. H. 2018. Interspecific gene exchange as a driver of adaptive evolution in Fungi. Annu. Rev. Microbiol. 72:377-398.

Fourie, A., Wingfield, M. J., Wingfield, B. D., van der Nest, M. A., Loots, M. T., and Barnes, I. 2018. Inheritance of phenotypic traits in the progeny of a Ceratocystis interspecific cross. Fungal Biol. 122:717-729.

Fourie, A., van der Nest, M. A., de Vos, L., Wingfield, M. J., Wingfield, B. D., and Barnes, I. 2019. QTL mapping of mycelial growth and aggressiveness to distinct hosts in Ceratocystis pathogens. Fungal Genet. Biol. 131: 103242.

Gibson, A. K., Refregier, G., Hood, M. E., and Giraud, T. 2014. Performance of a hybrid fungal pathogen on pure-species and hybrid host plants. Int. J. Plant Sci. 175:724-730.

Gladieux, P., Caffier, V., Devaux, M., and Le Cam, B. 2010. Host-specific differentiation among populations of Venturia inaequalis causing scab on apple, pyracantha and loquat. Fungal Genet. Biol. 47:511-521.

Guérin, F., Gladieux, P., and Le Cam, B. 2007. Origin and colonization history of newly virulent isolates of the phytopathogenic fungus Venturia inaequalis. Fungal Genet. Biol. 44:284-292.

Guérin, F., Franck, P., Loiseau, A., Devaux, M., and Le Cam, B. 2004. Isolation of 21 new polymorphic microsatellite loci in the phytopathogenic fungus Venturia inaequalis. Mol. Ecol. Notes 4:268-270. 
Holb, I. J., Heijne, B., and Jeger, M. J. 2005. The widespread occurrence of overwintered conidial inoculum of Venturia inaequalis on shoots and buds in organic and integrated apple orchards across the Netherlands. Eur. J. Plant Pathol. 111:157-168.

Jones, A. L., and Aldwinckle, H. S. 1991. Compendium of apple and pear diseases. St. Paul, Minn.

Klassen, W., and Curtis, C. F. 2005. History of the Sterile Insect Technique. Pages 3-36 in: Sterile Insect Technique. V. A. Dyck, J. Hendrichs and A. S. Robinson, eds. Springer, Dordrecht, The Netherlands.

Kohl, J., Scheer, C., Holb, I. J., Masny, S., and Molhoek, W. 2015. Toward an integrated use of biological control by Cladosporium cladosporioides H39 in apple scab (Venturia inaequalis) management. Plant Dis. 99:535-543.

Kuznetsova, A., Brockhoff, P. B., and Christensen, R. H. B. 2017. LmerTest Package: Tests in Linear Mixed Effects Models. J. Stat. Softw. 82:1-26.

Le Cam, B., Parisi, L., and Arène, L. 2002. Evidence of two formae speciales in Venturia inaequalis, responsible for apple and pyracantha scab. Phytopathology 92:314-320.

Le Cam, B., Sargent, D., Gouzy, J., Amselem, J., Bellanger, M. N., Bouchez, O., Brown, S., Caffier, V., De Gracia, M., Debuchy, R., Duvaux, L., Payen, T., Sannier, M., Shiller, J., Collemare, J., and Lemaire, C. 2019. Population genome sequencing of the scab fungal species Venturia inaequalis, Venturia pirina, Venturia aucupariae and Venturia asperata. G3. 9:2405-2414.

Le Gac, M., and Giraud T. 2008. Existence of a pattern of reproductive character displacement in Homobasidiomycota but not in Ascomycota. J. Evol. Biol. 21 :761-72.

MacHardy, W. E. 1996. Apple scab: biology, epidemiology, and management. APS press, St. Paul, Minnesota, USA.

Menardo, F., Praz, C. R., Wyder, S., Ben-David, R., Bourras, S., Matsumae, H., McNally, K. E., Parlange, F., Riba, A., Roffler, S., Schaefer, L. K., Shimizu, K. K., Valenti, L., Zbinden, H., Wicker, T., and Keller, B. 2016. Hybridization of powdery mildew isolates gives rise to pathogens on novel agricultural crop species. Nat. Genet. 48:201-205.

Murakami, J., Tomita, R., Kataoka, T., Nakayashiki, H., Tosa, Y., and Mayama, S. 2003. Analysis of host species specificity of Magnaporthe grisea toward foxtail millet using a genetic cross between isolates from wheat and foxtail millet. Phytopathology 93:42-45.

Passey, T. A. J., Robinson, J. D., Shaw, M. W., and Xu, X. M. 2017. The relative importance of conidia and ascospores as primary inoculum of Venturia inaequalis in a southeast England orchard. Plant Pathol. 66:1445-1451.R Core Team. 2020. R: A language and environment for statistical computing. R Foundation for Statistical Computing [http://www.R-project.org], Vienna, Austria.

Raabe, R. D., and Gardner, M. W. 1972. Scab of Pyracantha, Loquat, Toyon, and Kageneckia Phytopathology 62:914-916.

Rieseberg, L. H., Archer, M. A., and Wayne, R. K. 1999. Transgressive segregation, adaptation and speciation. Heredity 83:363-372.

Sanchez-Torres, P., Hinarejos, R., and Tuset, J. J. 2009. Characterization and pathogenicity of Fusicladium eriobotryae, the fungal pathogen responsible for loquat scab. Plant Dis. 93:1151-1157.

Sivanesan, A. 1977. The taxonomy and pathology of Venturia species. Bibliotheca Mycologica, Vaduz. 
Stukenbrock, E. H., Christiansen, F. B., Hansen, T. T., Dutheil, J. Y., and Schierup, M. H. 2012. Fusion of two divergent fungal individuals led to the recent emergence of a unique widespread pathogen species. Proc. Natl. Acad. Sci. U. S. A. 109:10954-10959. microsatellite markers and their application to population genetics of Venturia inaequalis. Phytopathology 89:748-753.

Tosa, Y. 1994. Gene-for-gene interactions between the rye mildew fungus and wheat cultivars. Genome 37:758-762.

Tosa, Y., H Tamba, H., K Tanaka, K., and S Mayama, S. 2006. Genetic analysis of host species specificity of Magnaporthe Oryzae isolates from rice and wheat. Phytopathology 96:480-484.

Vanderplank, F. 1944. Hybridization between Glossina species suggested new method for 
Page 16 of 17

349 Table 1. Description of the crosses between Venturia inaequalis f.sp. pomi (Pomi) and V. inaequalis f.sp.

350 pyracantha (Pyr) and pathogenicity of 251 progeny on apple

$\begin{array}{cc}\text { Pyr isolate } \quad \text { Pomi isolate } & \text { Number of progeny } \\ \text { non pathogenic on apple / tested on apple }\end{array}$

$1669 \quad$ EU-B04

$76 / 76$

$1381 \quad 2556$

44 / 44

1383

2556

44 / 44

1387

mixture of isolates

(104, 2416, 2429, 2444, 2557)

49 / 49

2299

mixture of isolates

(104, 2416, 2429, 2444, 2557)

38 / 38

351 


\section{Legends of the figures}

354

355

Figure 1. Pathogenicity of 32 isolates of Venturia inaequalis isolated from apple (Pomi), pyracantha (Pyr) or loquat (Loq) on two cultivars of apple, four cultivars of pyracantha and two cultivars of loquat. Each isolate was inoculated under controlled conditions on three plants of each cultivar. In red: presence of scab symptoms (with light red indicating less than $5 \%$ of the leaf area with scab symptoms), in blue: absence of scab symptoms, in white: not tested.

Figure 2. Boxplots of the percentage leaf area scabbed on two cultivars of loquat Alfonso and Peluche 21 days after inoculation with isolates of Venturia inaequalis isolated from three hosts: apple (Pomi in dark grey), pyracantha (Pyr in middle grey) and loquat (Loq in light grey). For each origin, five isolates were tested (Pomi: 190, 1395, 2315, 2367, EU-NL19; Pyr: 1669, 2267, 2269, 2299, 2309; Loq: 2258, 2264, 2300, 2303, 2304). Each isolate was inoculated under controlled conditions on three plants of each cultivar. The box represents the lower and upper quartiles. The thick horizontal line represents the median. The whiskers represent the highest and lowest values falling within 1.5 times the interquartile range. The black dots represent outliers. Pomi isolates are significantly less aggressive than Pyr and Loq isolates $(P=0.0095$ and $P=0.0164$, respectively, linear mixed effect model).

Figure 3. Percentage leaf area scabbed on the pyracantha cultivar Kasan after inoculation with 37 progeny of the cross between the Venturia inaequalis f.sp. pomi isolate EU-B04 (Pomi isolate) and the V. inaequalis f.sp. pyracantha isolate 1669 (Pyr isolate). The pathogenicity of the parents EU-B04 and 1669 are presented on the left and right sides, respectively. Each isolate was inoculated under controlled conditions on three plants of cultivar Kasan, and scoring was performed at four dates: 15, 20, 23 and 27 days post inoculation.

\section{Titles of the e-Xtras}

Table S1. Description of the origin of the Venturia inaequalis isolates used in the present study and indication of their mating type

Table S2. Simple Sequence Repeats used to check the clone status of each sampled isolate of Venturia inaequalis and the hybrid status of each progeny isolate 
Page 18 of 22

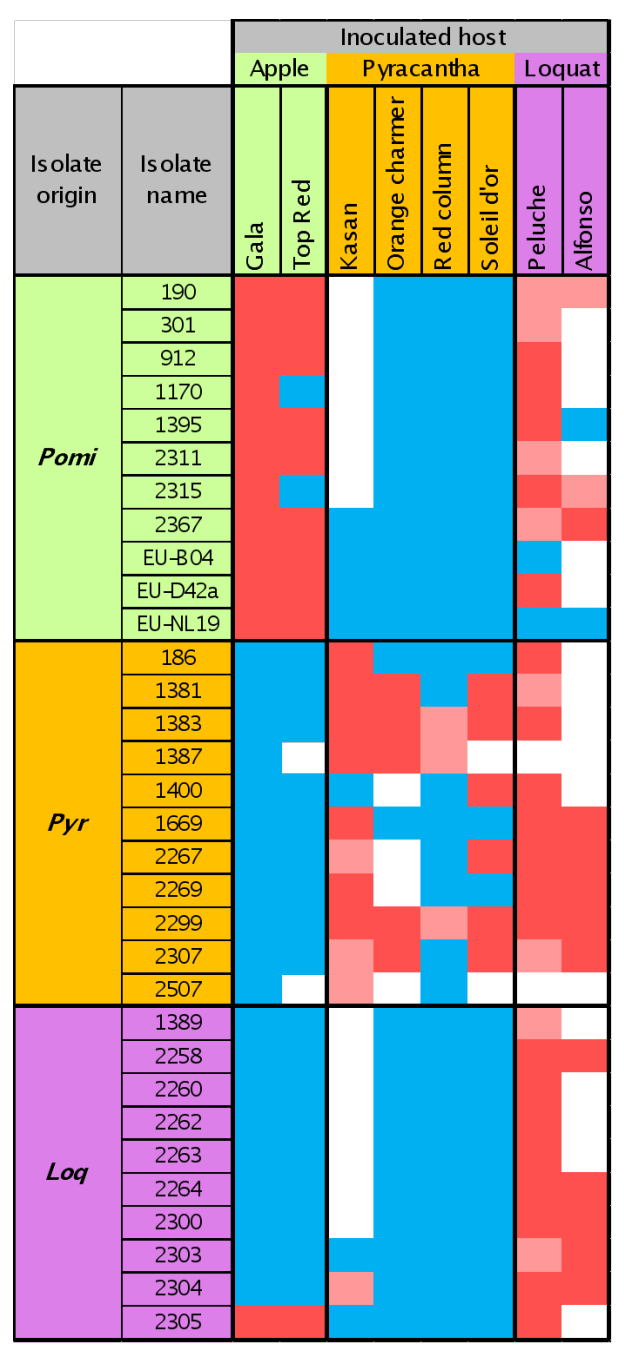




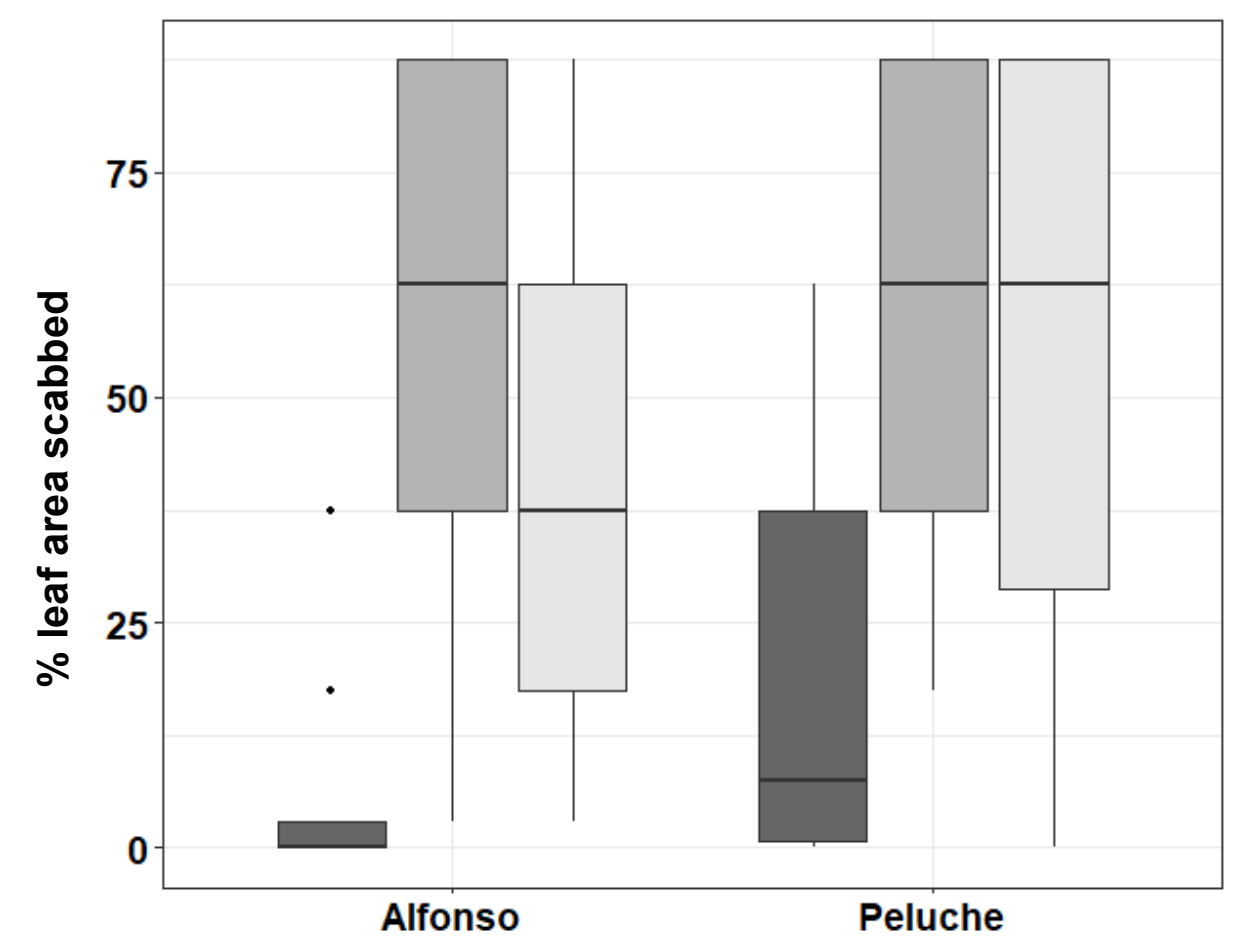




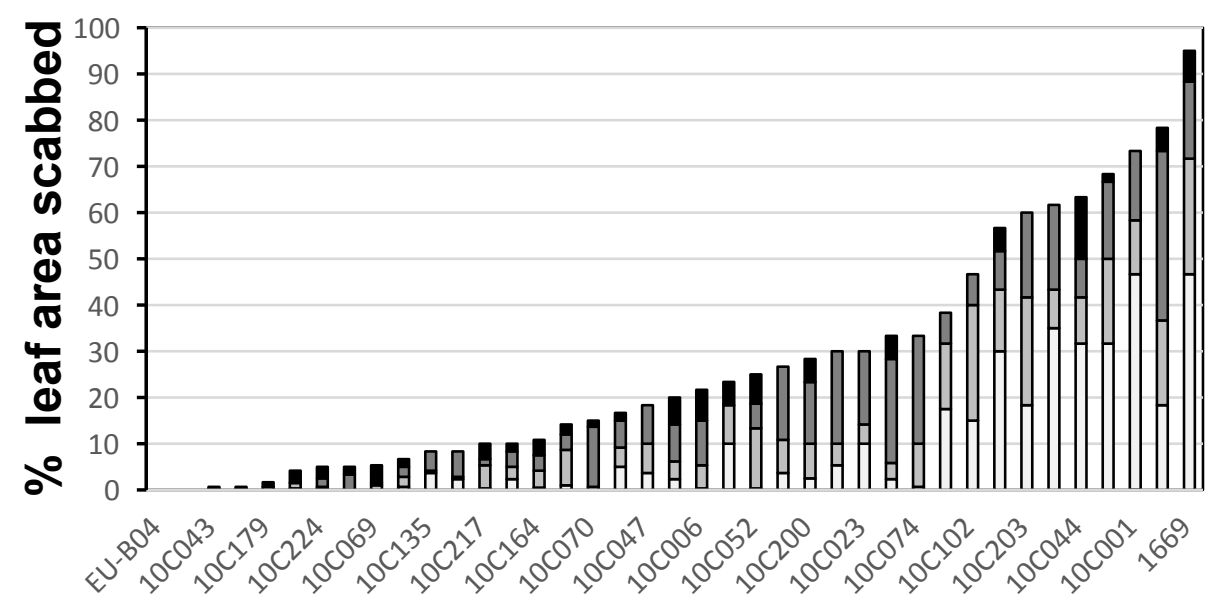

$\square$ mean 15dai $\square$ mean 20dai $\square$ mean 23 dai $\square$ mean 27 dai 
1 Table S1. Description of the origin of the Venturia inaequalis isolates used in the present

2 study and indication of their mating type

\begin{tabular}{|c|c|c|c|c|c|}
\hline $\begin{array}{l}\text { Host of } \\
\text { origin }\end{array}$ & Isolate & $\begin{array}{l}\text { Sampling } \\
\text { year }\end{array}$ & Sampling country & Sampling cultivar & Mating type \\
\hline Apple & 104 & 1978 & France & Golden Delicious & $a^{2}$ \\
\hline \multirow[t]{16}{*}{ (Pomi) } & 190 & 1987 & France & Golden Delicious & $a^{1}$ \\
\hline & 301 & 1988 & Germany & $81 / 19-53$ & $a^{2}$ \\
\hline & 912 & 1992 & Spain & unknown & $\alpha^{1}$ \\
\hline & 1170 & 1995 & The Netherlands & Discovery & $a^{1}$ \\
\hline & 1395 & 1995 & Colombia & Golden Dorsett & $a^{1}$ \\
\hline & 2311 & 2006 & Algeria & Gala & $\alpha^{1}$ \\
\hline & 2315 & 2006 & USA & Gala & $\alpha^{1}$ \\
\hline & 2367 & 2005 & China & Fuji & $a^{1}$ \\
\hline & 2416 & 2006 & France & $J 25$ & $a^{1}$ \\
\hline & 2429 & 2006 & France & $\mathrm{J} 25$ & $a^{1}$ \\
\hline & 2444 & 2007 & France & Gala & $a^{1}$ \\
\hline & 2556 & 2006 & France & $\mathrm{J} 108$ & $a^{1}$ \\
\hline & 2557 & 2009 & France & E063 & $a^{1}$ \\
\hline & EU-B04 & 1998 & Belgium & Golden Delicious Reinhardt & $a^{2}$ \\
\hline & EU-D42a & 1998 & Germany & Prima & $a^{1}$ \\
\hline & EU-NL19 & 1998 & The Netherlands & Golden Delicious & $a^{1}$ \\
\hline \multirow{11}{*}{$\begin{array}{l}\text { Pyracantha } \\
\text { (Pyr) }\end{array}$} & 186 & 1987 & Ireland & Red Column & $a^{2}$ \\
\hline & 1381 & 1998 & France & unknown & $a^{1}$ \\
\hline & 1383 & 1998 & France & unknown & $a^{1}$ \\
\hline & 1387 & 1998 & France & unknown & $a^{1}$ \\
\hline & 1400 & 1995 & Germany & unknown & $a^{1}$ \\
\hline & 1669 & 2001 & USA & unknown & $a^{2}$ \\
\hline & 2267 & 2003 & United Kingdom & Thornless & $a^{1}$ \\
\hline & 2269 & 2003 & Sweden & unknown & $a^{2}$ \\
\hline & 2299 & 2004 & France & unknown & $a^{1}$ \\
\hline & 2307 & 2004 & Chile & unknown & $a^{1}$ \\
\hline & 2507 & 2004 & Chile & unknown & $a^{2}$ \\
\hline \multirow{10}{*}{$\begin{array}{l}\text { Loquat } \\
(\text { Loq) }\end{array}$} & 1389 & 1999 & France & unknown & $a^{1}$ \\
\hline & 2258 & 2006 & Marocco & unknown & $a^{1}$ \\
\hline & 2260 & 2006 & Portugal & unknown & $a^{1}$ \\
\hline & 2262 & 2004 & France & unknown & $a^{1}$ \\
\hline & 2263 & 2006 & Spain & Algerie & $a^{2}$ \\
\hline & 2264 & 2006 & Spain & unknown & $a^{1}$ \\
\hline & 2300 & 2006 & Iran & unknown & $a^{1}$ \\
\hline & 2303 & 2004 & New Zealand & unknown & $a^{1}$ \\
\hline & 2304 & 2004 & New Zealand & unknown & $a^{1}$ \\
\hline & 2305 & 2003 & Chile & unknown & $a^{1}$ \\
\hline
\end{tabular}

3

$4{ }^{1}$ Mating types defined with primer sequences $\mathrm{F}$ : CCCCTCTGACTCTGAACAGC and R: TGTCGAAATCGTCACTCTGC for Mat a,

5 and primer sequences F: CACCTCTTTCCAGCAGAAGG and R: CGATCTGCAGGAACTTGTCA for Mat $\alpha$

62 Mating types defined by genome sequencing (Le Cam et al., 2019) 
Page 2 of $\mathbf{2}$

Valérie Caffier

Phytopathology

8 Table S2. Simple Sequence Repeats used to check the clone status of each sampled isolate of

9 Venturia inaequalis and the hybrid status of each progeny isolate

\begin{tabular}{|c|c|c|c|c|c|}
\hline Primer name & Primer sequences $\left(5^{\prime}-3^{\prime}\right)$ & Primer locus & Reference & $\begin{array}{l}\text { Clone } \\
\text { status }\end{array}$ & $\begin{array}{l}\text { Hybrid } \\
\text { status }\end{array}$ \\
\hline M1 & $\begin{array}{l}\text { F: [HEX]TCGAGATCCTCAAACTTCCTT } \\
\text { R: TTTTAACTGTGCGGCCTG }\end{array}$ & $1 \mathrm{tc} 1 \mathrm{a}$ & Tenzer et al, 1999 & $x$ & $x$ \\
\hline M2 & $\begin{array}{l}\text { F: } \\
\text { [FAM]CGATTGGGGATATGAAGACTT } \\
\text { R: TTAGTAATCAAATCGCACCCA }\end{array}$ & $1 \mathrm{tc} 1 \mathrm{~b}$ & Tenzer et al, 1999 & $x$ & $x$ \\
\hline M4 & $\begin{array}{l}\text { F: [FAM]AGCGCTAGGTCGTGAAATC } \\
\text { R: TTTCTGAAGTGTGTGGGACAT }\end{array}$ & $1 a a c 3 b$ & Tenzer et al, 1999 & $x$ & \\
\hline M15 & $\begin{array}{l}\text { F: } \\
\text { [TAMRA]GCACCTGCTCTGTCTATCTC } \\
\text { R: AAGGTTCAGGCACTGGAG }\end{array}$ & Vica9/152 & Guerin et al., 2004 & $x$ & \\
\hline M20 & $\begin{array}{l}\text { F: [TAMRA]TGTCAGCCACGCTAGAAG } \\
\text { R: CACCGGACGAATCATGC }\end{array}$ & Vicacg8/42 & Guerin et al., 2004 & $x$ & $x$ \\
\hline M42 & $\begin{array}{l}\text { F: [TAMRA]CCAGACCTCCTTATTCAC } \\
\text { R: TAACTCCTGAAGACGGCATG }\end{array}$ & & Guerin et al., 2007 & $x$ & $x$ \\
\hline M43 & $\begin{array}{l}\text { F: [HEX]GCCTGGTTGTGGATCTGTC } \\
\text { R: ATCCTGCTACATCGACCTTC }\end{array}$ & Viga7/116 & Guerin et al., 2004 & $x$ & $x$ \\
\hline M51 & $\begin{array}{l}\text { F: [HEX]TCGCGCATCACTATCTACAC } \\
\text { R: AGACAGGAATGTGGTGGAAG }\end{array}$ & Vica9/X & Guerin et al., 2004 & $x$ & \\
\hline 283036 & $\begin{array}{l}\text { F: [6- } \\
\text { FAM]CAAGCTGAAAGGGCAAAGAG } \\
\text { R: ATATGGGGCATTGGGAAACT }\end{array}$ & & Sargent, unpublished & & $x$ \\
\hline 276191 & $\begin{array}{l}\text { F: [6- } \\
\text { FAM]TGAGGGGAGAGATTTTGGTG } \\
\text { R: ATGGTGGGGCTTGACTAATG }\end{array}$ & & Sargent, unpublished & & $x$ \\
\hline 139795541 & $\begin{array}{l}\text { F: } \\
\text { [HEX]GTGGTTATGTTGTGGGAGTGG } \\
\text { R: GTACTCTCTCGGCCTAAACTCG }\end{array}$ & & Sargent, unpublished & & $x$ \\
\hline
\end{tabular}

10 